\title{
Erratum to: Isolation of novel microsatellites for the howler monkey bot fly Cuterebra baeri (Diptera: Cuterebrinae)
}

\author{
Katharine Milton · Jeffrey D. Lozier •
}

Eileen A. Lacey

Published online: 15 February 2011

(C) Springer Science+Business Media B.V. 2011

\section{Erratum to: Conservation Genet Resour DOI 10.1007/s12686-010-9366-3}

Please note the following correction to Fig. 1:

Some of the numbers provided within the bars of Fig. 1, indicating the number of bot fly larvae pairs involved in each average relatedness calculation, were summed incorrectly; black bars should read 23 for 2003, 26 for 2005, 21 for 2007 , and 288 for 2009 , while gray bars should read 5 for 2003, 2 for 2005, 7 for 2007, and 147 for 2009.

The online version of the original article can be found under doi:10.1007/s12686-010-9366-3.

K. Milton $(\bowtie)$

Department of Environmental Science, Policy and Management, University of California, Berkeley, CA 94720, USA

e-mail: kmilton@berkeley.edu

J. D. Lozier

Department of Entomology, University of Illinois,

Urbana, IL 61801, USA

E. A. Lacey

Museum of Vertebrate Zoology and Department of Integrative

Biology, University of California, Berkeley, CA 94720, USA 